2019-08-01

\title{
Behind the cloak of competence: Brain Injury and Mental Capacity Legislation
}

\author{
Moore, S
}

http://hdl.handle.net/10026.1/14224

10.1108/JAP-02-2019-0007

Journal of Adult Protection

Emerald

All content in PEARL is protected by copyright law. Author manuscripts are made available in accordance with publisher policies. Please cite only the published version using the details provided on the item record or document. In the absence of an open licence (e.g. Creative Commons), permissions for further reuse of content should be sought from the publisher or author. 


\section{Behind the cloak of competence: Brain Injury and Mental Capacity Legislation}

\begin{tabular}{|r|l|}
\hline Journal: & The Journal of Adult Protection \\
\hline Manuscript ID & JAP-02-2019-0007.R2 \\
\hline Manuscript Type: & Research Paper \\
\hline Keywords: & $\begin{array}{l}\text { mental capacity, brain injury, case management, social care, executive } \\
\text { impairment, lack of insight }\end{array}$ \\
\hline \multicolumn{2}{|l}{} \\
\hline
\end{tabular}

\section{SCHOLARONE \\ Manuscripts}




\begin{abstract}
Purpose: Brain Injury Case Managers (BICMs) work closely with individuals with Acquired Brain Injury $(\mathrm{ABI})$, assessing needs, structuring rehabilitation interventions and providing support, and have significant experience of clients with impairments to decision-making. This study explored the application of the Mental Capacity Act (MCA) and its guidance when applied to $A B I$ survivors. This research aimed to 1) highlight potential conflicts or tensions that application of the MCA might pose and 2) identify approaches to mitigate the problems of the MCA and capacity assessments with $A B I$ survivors. It is hoped this will support improvements in the services offered.

Design: Using a mixed method approach, 93 BICMs responded to an online questionnaire about decision-making following $\mathrm{ABI}$. Of these, $12 \mathrm{BICMs}$ agreed to take part in a follow-up semi-structured telephone interview.
\end{abstract}

Findings: The data revealed four main themes: disagreements with other professionals, hidden disabilities, vulnerability in the community and implementation of the MCA and capacity assessments.

Practical Implications: The findings highlight the need for changes to the way mental capacity assessments are conducted and the need for training for professionals in the hidden effects of $\mathrm{ABI}$.

Originality: Limited research exists on potential limitations of the application of the MCA for individuals with an ABI. This study provides much needed research on the difficulties surrounding mental capacity and $A B I$. 


\section{Introduction}

Incidence of $A B I$ : The incidence of acquired brain injury $(A B I)$ is a significant concern with 348,453 admissions to hospitals due to ABI with the United Kingdom (UK) in 20162017 (954 admissions daily; Headway, 2018). The most commonly reported causes of $\mathrm{ABI}$ in the UK are bleeds to the brain, infections, or traumatic brain injuries (TBIs) caused by falls, assaults, and road traffic accidents (Rutland-Brown et al., 2006). The consequences experienced by survivors can have a significant impact on their day-today living and often requires long term care and support (Khan et al., 2003).

Impact of $A B I: A B I$ is one of the leading causes of disability within the UK (Fleminger and Ponsford, 2005) with individuals experiencing changes emotionally, cognitively and behaviourally (Yates et al., 2006). Some may experience a range of physical difficulties, including loss of coordination, speech difficulties, fatigue, and sexual problems (Headway, 2018). However, for many individuals there will be no physical indication of impairment (Higham and Phelps, 1998). Cognitive difficulties can include memory impairment (Mathias and Mansfield, 2005), reduced processing speed (Felmingham et al., 2004), executive impairment (Chan et al., 2008) and attentional deficits (Rohling et al., 2009), and can be seen as a "silent epidemic" (Langlois et al., 2006).

Executive functioning incorporates skills such as planning, cognitive flexibility, multitasking, initiating behaviour, inhibition, controlling emotions, and learning social "rules" (Gioia et al., 2008). Executive dysfunction is often invisible and therefore not easily assessed with formal neuropsychological assessment (Parsons et al., 2017; Manchester et al., 2004). It can have a significant impact on functioning (Rabinowitz and Levin, 2014), and has been linked to risk-taking behaviours such as substance 
and alcohol misuse (Parry-Jones et al., 2004; Weil et al., 2016), criminal activity (Holloway, 2014) and suicidality (Simpson and Tate, 2002; Homaifar et al., 2012).

Mental Capacity Act (MCA): The Mental Capacity Act (MCA) is a legal framework to guide the assessment of an individual's capacity to make decisions. Capacity can be affected by an individual's inability to understand information pertaining to decisionmaking, their ability to retain information, their ability to weigh up and use that information and their ability to communicate. Capacity can also fluctuate over time. A person is considered to lack capacity if they are unable to make decisions due to an impairment or disturbance in the functioning of the mind or brain (Department of Health [DoH], 2005). There are five statutory principles to the MCA; a person 1) must be assumed to have capacity unless it is proven otherwise, 2) must not be treated as unable to make a decision unless all practicable steps have been made to help and 3) must not be treated as lacking capacity merely based on unwise decisions. The final principles state that those lacking capacity should have decisions made in their best interests () and that before a decision is made, it must be ensured that the purpose for which it is made cannot be achieved in a way that is less restrictive to their rights (5).

Professionals, researchers and family members have argued that the act does not meet the needs of individuals with a range of different conditions, including $\mathrm{ABI}$ (House of Lords Select Committee [HoLSC, 2014]). For example, the link between executive dysfunction and increased risk-taking behaviours brings the capacity to make decision regarding lifestyle choices, welfare and health into question. There is limited research and guidance on the MCA's description of 'unwise decisions' and whether this constitutes these kinds of risk-taking behaviours. The HoLSC (2014) report highlighted 
several issues with the MCA and its implementation. Evidence provided to the Select Committee related to $\mathrm{ABI}$ identified the impact lack of insight has upon decisionmaking and upon the assessment of mental capacity. Insight is an individual's partial, or whole, awareness of changes in their abilities, functioning and emotional responses secondary to their injury (Holloway and Fyson, 2016; Ownsworth et al., 2006; Prigitano, 2005). An ABI survivor may be able to describe their difficulties (intellectual awareness) and even acknowledge strategies to deal with these. However this knowledge may not manifest or affect behaviour within real-life settings (Holloway and Fyson, 2016).

The functional test of capacity identified four areas in which capacity may be impaired, through an inability to 1) understand information provided, 2) retain information long enough to make a decision, 3) weigh up information available to make the decision and 4) communicate their decision. A lack of insight affects the individual's ability to use relevant information and weigh it up in order to make a decision (Prigitano, 2005). Although it is a salient effect of $A B I$, it is important to note that somewhat nebulously defined concepts, such as "lack of insight", though common in practice and clinical discourse, are not used within the wording of the MCA. A lack of insight into the impact of one's brain injury does not, de facto, equate to an individual having a lack of Capacity with regards a specific decision. It is essential that BICMs, and others, to remain compliant with the Act and Code of Practice, relate this perceived brain injury related difficulty to the functional tests of understanding, retaining, weighing up and using and communicating information relevant to the decision in hand (Case, 2016). The evidence for this is likely to come from open discussion with family and those working closely with the individual who are more likely to understand the nuances of 
their $\mathrm{ABI}$ and the effects these have on their decision-making capacity (Douglas and Bigby, 2018). The MCA guidance clearly highlights the importance of including others in the assessment process (NICE, 2018).

A review of contested cases relating to Mental Capacity before the Courts identified that of the functional tests, it was "weighing up and using" that appeared to be the one that was most frequently noted to be cited as the reason for perceived lack of capacity (Ruck Keene et al., 2019). The authors of this study note that the whole concept of "using and weighing up" is a newer legal construct and one that will need more attention in both clinical and legal research to better clarify.

Thornton (2011) identified potential conflict between two core principles of the MCA. The first being that assessment of capacity must be decision-specific; being deemed to lack capacity to make a particular decision does not mean that capacity is lacking to make another decision. Thornton (2011) claims that this is potentially at odds with the principle that capacity should be assessed as being independent of the 'wisdom' of the decision being made as multiple 'unwise decisions' may be indicative of an impairment in capacity. This hints at an ambiguity over what differentiates a "lack of capacity", from an 'unwise decision'. Differences of opinion regarding what is an "unwise" decision, a "lifestyle-choice" and an incapacitous decision are central to conflicts relating to the implementation of the MCA. Tensions have developed between a potentially paternalistic risk-averse and controlling approach and the abandonment of brain-injured people to the impact of their cognitive and executive impairments in 
the context of a society that does not recognise and respond to their needs (HoLSC, 2014; Flynn 2016; Norman 2016).

A lack of knowledge of $\mathrm{ABI}$ and the invisible disabilities that characterise it, can lead professionals to treat an individual's decision as being a result of their own free will, not as a result of a lack of capacity to make an informed choice (Flynn, 2016). This can result in individuals making repeated unwise decisions, with direct impact on themselves and others, but still being deemed capacious, sometimes with fatal consequences (Preston-Shoot, 2018; Flynn, 2016).

Additionally, standardised capacity assessments do not take into account the impact of emotional state on decision-making (Beadle-Brown, 2015). Within the MCA guidance, the examples of assessments place emphasis on making information available, rather than assessing real-life, dynamic situations (Brown and Marchant, 2013). Thus, when the individual steps out of this structured environment, and is required to make complex multi-faceted decisions that may have an emotional component, problems may arise which may affect their safety and wellbeing (Brown and Marchant, 2013). The implementation of the MCA and assessment in this way can lead to wrongful assumptions of capacity that leave survivors in vulnerable situations without appropriate support and safeguarding in place (George and Gilbert, 2018).

Should an individual be deemed to lack capacity, the MCA enables professionals to make a 'best interest' decision on their behalf. What exactly constitutes a 'best interest' decision is also unhelpfully vague. Marshall and Sprung (2017) reviewed the literature from 2007-2016 and found that professionals lack confidence in understanding and 
making best interest decisions. They concluded that this confusion was a result of a lack of knowledge from professionals regarding MCA legislation as a whole (Marshall and Sprung, 2017).

Case Management: Case management is a process devoted to the coordination, rehabilitation, care and support of individuals with complex needs, with the aim of facilitating independence to improve quality of life for individuals, whilst taking into account personal preferences, the social and familial context and issues of risk management (Clark-Wilson, 2006). British Association of Brain Injury Case Managers (BABICM) members are usually qualified and registered professionals from a range of health and social care backgrounds, most especially Occupational Therapy, Nursing and Social Work and have a specialist knowledge of the nuances and complexities of ABI (Holloway and Fyson, 2016).

The study aimed to explore the views and experiences of BICMs working within the MCA and its relevant guidance to 1) highlight potential conflicts or tensions that application of the MCA might pose when applied to individuals affected by $A B I$ and 2) identify approaches to mitigate the problems of the MCA and capacity assessments with individuals with $\mathrm{ABI}$.

\section{Method}

Participants: Participants were recruited through the British Association of Brain Injury Case Managers (BABICM). Ninety-three participants completed the online survey in the first stage of the study. All participants had experience of working with clients with $A B I$ in the last five years. Experience ranged from BICMs who had worked with less than four clients in the last five years through to those that had worked with over 20 
(mean $=13.2$ clients). Of the original sample, 12 participants agreed to take part in further semi-structured interviews in the second phase of the study. Ethical approval was granted from the University of Plymouth, Faculty of Health and Human Science Research Ethics Committee.

Design and Procedure: The project employed a mixed-methods research design (Hanson et al., 2005). This was chosen as mixing different methods can strengthen a study by neutralising some of the disadvantages of the models, as well as incorporating the benefits of both (Creswell et al., 2003; Johnson et al., 2007). Furthermore, triangulation of findings within a mixed-method approach is a way of ensuring credibility of the research, and thus increases the trustworthiness of the findings (Ravalier, 2018). The online questionnaire was administered via the survey platform Survey Gizmo and contained both qualitative free text sections and quantitative questions taking the form of predominately Likert scales.

Quantitative data were analysed using descriptive statistics and correctional analyses where appropriate. Qualitative data were analysed using conventional content analysis. At the end of the questionnaire, participants were given the option to provide their email address if they wish to take part in the semi-structured interviews. Of the 18 participants who expressed an interest, 12 took part in the second phase.

Semi-structured interviews were conducted over the telephone using a series of prompt questions designed to elicit elaboration on the key themes raised from the original survey data (e.g. can you describe some of the issues you have encountered regarding the assessment of capacity in your clients?) Interviews lasted between 30 
minutes and one hour and audio-recorded for later transcription using an orthographic method where every spoken word was transcribed verbatim. The transcribed interviews were then analysed using a mixed thematic approach.

Data Analysis: The data from the online questionnaire were analysed using a mixed methods approach whereby quantitative questions were analysed using descriptive statistics and where appropriate correlations were conducted to assess the relationships between responses to questions. The qualitative sections were then analysed using conventional content analysis (CCA) to provide a deeper understanding of the issues associated with supported decision-making with $A B I$ survivors. Data were analysed separately and then combined using a triangulation approach (Hanson et al., 2005). As the qualitative responses were designed to elicit information about a topic with limited pre-existing literature, CCA was used to explore the data (Hsieh and Shannon, 2005) as it allows direct information to be gathered from the participants responses, without placing it in predefined categories (Hsieh and Shannon, 2005). Analysis began with reading the data repeatedly to gain a complex understanding of the responses (Tesch, 1990) and writing exploratory comments. Reponses were read again to derive codes within the data that capture key thoughts and concepts (Miles and Huberman, 1994). These codes were then organised into related categories and then meaningful clusters (Patton, 2002), which identified the master themes. A validation analysis of the codes was conducted by another member of the project team. Further validity checks took place through integration with the responses to the interview questions. 
The interview data were analysed using a mixed thematic approach using deductive and inductive methods, as described by Braun and Clarke (2006). An initial deductive framework was applied to the data in order to identify pre-constructed themes based on the CCA conducted from the questionnaires. A further inductive analysis was subsequently applied to the data, in order to look for any new themes that had not formed part of the original analysis. This triangulation process led to a restructuring of the data collected in stage one of the study. Validity checks were performed on the data by other members of the research team.

\section{Results}

Quantitative survey findings: BICMs were asked to rate how many clients with $\mathrm{ABI}$ they had seen in the last five years, the number with multiple capacity issues (more than one decision where capacity was questioned) and the numbers of those with fluctuating capacity (Figure 1). Over half the participants $(62 \%)$ reported that they had experiences where clients have made unwise decisions but were thought to have capacity following an assessment by other professionals who were often not brain injury specialists. In the past five years, over half of BICMs (63\%) reported having disagreements with other professionals/services regarding the capacity of a client. This was picked up as a theme in the qualitative analysis and discussed below. In the written responses, the most commonly highlighted issues were regarding the welfare of clients, risk-taking behaviours and living arrangements. When asked to rank the domains in which participants felt their clients would be most likely to demonstrate a lack of capacity "weighing up and using" the information relevant to a decision was ranked highest, followed by "understanding information". Difficulties with communication and retention of information were ranked as being less problematic. 
This potentially indicates that it is easier to support retention and communication issues in clients to support decision-making than it is to compensate for cognitive impairment, particularly executive impairment in practice and functioning.

\section{Insert Figure 1 here}

All BICMs that responded reported supporting their clients with making decisions. However, the majority of participants $(73 \%)$ responded that they were not aware of any specific resources to support this process. BICMs identified the need to help clients generate ideas (48\%), help clients consider pros and cons of outcomes (58\%), support clients to see the potential implications of outcomes (57\%) and $58 \%$ reported that they provide written feedback to clients to support decision-making.

Participants in the survey considered the involvement of others, mainly family, and the client in the decision-making process. Just over half of participants (53\%) agreed that they support clients by engaging trusted family members and others with decisionmaking conversations. In contrast, $61 \%$ neither agreed nor disagreed that family members are best placed to support decision-making, with $30.1 \%$ disagreeing and $1.6 \%$ strongly disagreeing. This was also picked up in the qualitative analysis in the consideration around financial abuse. Finally, 65\% of participants reported that knowing the client and family well helped them support decision-making and $34 \%$ agreed that their relationship with the client was the main factor in supporting decisionmaking. Working with clients and their families allows BICMs to build good relationships with them. This close relationship aids supported decision-making and was highlighted in the qualitative analysis, with BICMs reporting a lack of relationship 
and understanding of clients by professionals who undertake capacity assessments as a reason for discrepancies between assessments.

A series of correlational analyses were conducted to identify relationships in the data set. A significant correlation was found between the number of clients case managed and the number of clients with fluctuating capacity $r(66)=.411, p<.001$, between the number of clients managed with capacity issues and the number of clients with fluctuating capacity $r(64)=.423, p<.001$. These findings suggest that more experienced BICMs have greater experience of working with clients with capacity issues and may be better placed to identify difficulties. A significant correlation was also found between the number of clients with multiple capacity issues and BICMs response to providing feedback in writing to support their clients $r(59)=.301, p<.05$, highlighting, perhaps, that more experienced BICMs were more likely to provide written feedback as a way to support decision making.

Qualitative findings: As part of understanding the issues surrounding mental capacity and the need for supported decision-making, participants were encouraged to provide qualitative feedback on their experiences. The qualitative analysis identified four main themes; disagreements with other professionals, implementation of the MCA and mental capacity assessments, $A B I$ as hidden disability and the vulnerability of $A B I$ survivors (see Figure 2).

\section{Insert Figure 2 here}


Theme 1: Disagreements with other professionals: The quantitative data identified that $92 \%$ of BICMs reported having disagreements with other professionals over the capacity of their clients to make decisions with one participant stating that they occur "on a day to day basis". BICMs discussed instances of contradictory assessments taking place that suggested capacity despite poor insight and high levels of executive impairment, cases where non-specialist professionals failed to undertake assessments where they were warranted, and instances of ill-informed assessments being conducted by non-specialist professionals. BICMs identified five main reasons for disagreements with professionals;

- a lack of knowledge of $A B I$ by non-specialist professionals

- "false" appearances of capacity by individuals who sound more competent in discussion than in practice

- a lack of collaboration by assessors with family members or involved professionals

- the framing of questions, the "question and answer" method of assessment

- professionals having their own agenda (see figure 2).

The most common sub-theme was of other professionals "undertaking assessments [without] [...] a clear understanding of brain injury". The majority of these experiences referred to individuals employed by statutory services. Social services employees received the most criticism "because they don't have the knowledge of brain injury [...] they don't know the kind of questions that they need to ask [...] and they take everything that they see at face value". It was also noted that the "invisible" difficulties of $\mathrm{ABI}$ meant that other professionals often missed the "subtleties about actually how 
vulnerable they are". Participants explained how these disagreements hindered their ability to support clients by preventing access to funds or access to safeguarding.

\begin{abstract}
"We couldn't apply for funding, we had to wait months before another person came out to come to the pretty obvious conclusion that this person does not have capacity". (Interview participant $(P) 2$ ).

"...actually stops any safeguards being put in place and [...] stops them from being supported to be able to make decisions". (P2).

"Where client was deemed to have capacity to make decisions about medication but repeatedly forgot the reasoning and they failed to take it". (Survey participant (S)161)

"Client was assessed as being able to have sexual relationships. She subsequently slept with numerous partners who she believed loved her...she was subsequently raped". (S124).
\end{abstract}

All participants reported assessors taking what clients say "at face value" due to a failure to understand how hidden disabilities, such as lack of insight and executive impairments, impact upon real world functioning. When paired with intact intellectual ability and retained social skills, these executive impairments may mean that clients may have a "cloak of competence" which results in the false appearance of capacity. The difference between the presentation of clients during an office-based assessment and their functioning in the real world ran throughout this discussion.

\footnotetext{
"The reality is, they can talk the talk but they can't follow it through, if they encounter any problem, if there's any distraction, if there's anything on their mind, some days they'll initiate it but others they don't. Their difficulties are completely changeable day by day and people don't believe it because the person presents very very well with this cloak of competence." (P6).

I have found that my clients can sometimes understand information given to them about a significant decision, and can take part in a discussion of pros and cons about the decision, but are not able to take those discussions into account when they are alone and in the heat of the moment". (S58).
}

Many participants described the failure, and sometimes refusal, of other professionals to collaborate with BICMs. Some participants explained how other professionals are "dismissive" and seem to be "suspicious" of BICMs because they work in the private 
sector so are "sometimes [...] seen as outsiders" or thought of as being "in it to make money".

"Certainly within social services, they're very suspicious of solicitors and don't talk to them and you know 'they're always on the make' [...] case management is also being tarred with the same brush". (P10).

Participants noted that when other professionals seek out the perspectives of others, this is often limited to family members. Participants highlighted that in some instances these family members may not always have a client's best interests at heart, putting clients at risk. One participant described a client whose father, he believed, had motivations to "get his hands on his son's money" and how a neuropsychologist was unaware of this and involved him in the decision-making process with his son. He explained how this caused "havoc [...] and had that neuro-psychologist then come and had a chat with us about the father [...] it would have been a lot easier".

Participants also explained how some assessors "ask [...] questions in the way that facilitates just getting the open response, rather than any direct questions" and how professionals who lack knowledge of $A B I$ fail to understand the framing of a question, can influence a client's response.

\begin{abstract}
"Any question that he had directed towards him, would influence his response in the way of the phrasing of the question and the type of question, whereas if it was an open question he couldn't answer it, but [...] if it was [...] a direct question that was expecting the answer 'no' he would say 'no'. Everything from statutory services is generally at face value and [...] because the clients can say yes, they think that they've got the capacity to make that decision". (P1).
\end{abstract}

Participants' suggested that professionals may have their own agendas which influence capacity assessments. This discussion focused on the pressures 
experienced by statutory services who have large caseloads and limited finances and time to spend with service-users. It was theorised that this led to some professionals failing to engage with BICMs:

\begin{abstract}
"It's an easy life if you go 'well they said they planned it so its fine here's the money' rather than ask the question", and another participant stated that "there's a certain level of complacency across the board of practitioners who are just doing it [...] 'cause they have to [...] it's a tick-box exercise". (P12).
\end{abstract}

Theme 2: Hidden disabilities: Participants explained that many assessors do not understand the variation and extent of the hidden disabilities associated with $A B I$, which led to clients being deemed, wrongly, to have capacity. As one participant summarised, “you really can't judge somebody's capacity if you don't understand the underlying problems". Specifically case managers identified that a lack of knowledge of executive dysfunction, lack of insight, initiation problems, difficulties with idea generation and communication difficulties, the impact of mood and environment on decision-making and, fluctuations in capacity can lead to inappropriate assumptions of capacity.

Executive dysfunction was identified as "the biggest issue and [...] the most challenging in terms of assessment". One participant explained how other cognitive difficulties like poor memory are "more tangible" as it is easier to assess an individual's ability to retain information, while another explained how they influence assessments "because they can [...] mask issues [...] like [...] planning, and they know in the moment [...] how to answer [in] [...] assessment settings". Another participant stated that "executive skills are [...] difficult to grasp if [the assessor has] [...] never had training" and described executive dysfunction as "a stumbling block" that is "not really specifically covered in the Mental Capacity Act". 
A lack of insight was identified as "massively" affecting their clients' capacity and makes them more vulnerable as not being "able to recognise their difficulties" means that "they can put themselves in so many difficult situations where they can become a target for physical, verbal, [and] financial abuse". One participant explained how an individual they worked with is "not able to present to anybody the sort of support that they need [...] or they're not able to identify for themselves what potential risks they might be taking, so they're not even identifying what the information is that they need to be weighing up". Another recurring point was that many professionals struggle to understand this because "it's very abstract in nature".

\begin{abstract}
"Someone not being able to [...] realise that [...] they can't do a drumroll because they haven't got one arm and [...] arguing that they can [...] seems a very strange concept and that's a really obvious lack of insight, but [...] our clients all the time say 'I can manage my money, I want more money' and [...] then they'll spend it all and [...] and [...] it's just a repeating cycle". (P9).

"Lack of insight, executive issues, processing information, understanding the context of the decision in situ, generating ideas and problem solving, and seeing the implications of the decision in reality. Prospective decision making can be tricky, if the context is not fully understood or able to be put into practice. Vulnerabilities and influence from others, for instance, in the phrasing of questions and doing what others want them to do rather than independent decision making. Fluctuations of mood, effects of anxiety, rigidity of thinking and lack of empathy impacts on decisions". (S50).
\end{abstract}

Associated with executive impairments, BICMs identified that professionals often do not understand that what a client may say during a structured, office-based assessment, is drastically removed from what they are capable of outside of that environment. Participants described how mood and the environment, specifically distractors and stressors, can worsen clients' hidden disabilities; "their ability to manage and mediate [...] executive skills are hugely impacted by their emotional regulation". 
Discussion of the impact of the environment was very much focused on the view that assessing capacity in a very structured, office-based setting was not suitable for $A B I$ as this does not take the effects of environment into account. One participant explained how she might support a client to come to a decision, but that "when you leave and they're in the real world [...] being bombarded with information within the community or they're struggling with impulse control [...] they stumble at the first hurdle because in real life they often can't initiate doing that thing". Initiation problems were also highlighted as a problem during office-based assessments as the ability to discuss action in such a setting does not equate to the ability to initiate and implement those decisions outside of that setting and that "assessors are often not aware of or misunderstand [this] [...] difference".

Fluctuating capacity came into much of the discussion of executive dysfunction, and of the impact of mood and the environment. One participant described it as "the red mist" that means that clients "can really struggle in the heat of the moment to enact sensible plans and apply them". Participants also highlighted how working with clients for a long duration of time, meant that they could support their clients more effectively, as they were "able to [...] see how their capacity might fluctuate" and develop a greater understanding of "what affects it [...] and what supports it".

In relation to the difficulties of how questions are framed in assessments, participants highlighted that idea generation problems can often be overlooked during assessments of capacity. The appearance of capacity during assessments does not mean that clients are able to generate ideas in order to begin making those same decisions when at home in the presence of stressors and distractions. 
"You might say to a client "oh what do you want to eat today?" and they'll say "oh I'm not hungry" but actually it's not because they're not hungry it's because they can't generate an idea of what they might want to have [...] if you went to them and said "would you like pizza or pasta today?" they'll go "I want pizza" because you're generating that idea and they're making a choice." (P9).

Memory problems were often discussed in relation to unwise decisions and lack of insight. Participants described how these impairments meant that clients frequently do not believe them when they remind them of times when unwise decisions have ended badly and how often "they believe that they are correct even if you showed them something that's been written down [...] it doesn't mean a lot to them".

Finally, $33 \%$ of participants highlighted communication difficulties as a factor that influences their clients' presentation during capacity assessments, as participants emphasised the importance of using "communication aids like talking mats" and "making sure that the clients have had all the opportunity to communicate and that actually their levels of communication are accurately assessed". One participant explained that typically she finds that with clients with "profoundly injured [...] level[s] of understanding, their level of communication tends to be overestimated [...] because [...] they may have retained some of the social elements of language and communicating, the nodding and smiling, turn-taking" and so "people tend to think they understand much more than they actually do".

Theme 3: Vulnerability in the community: Participants talked at length about their concerns that non-ABI-specialist professionals often failed to appreciate the level of vulnerability of $A B I$ survivors in the community. The term vulnerable has connotations associated with legal frameworks around protecting "vulnerable adults", a term that is no longer used. Vulnerability in this context is used more generally to reflect a 
population who are at risk from harm, abuse or self-neglect. Thus we are using a wider dictionary definition of the term rather than a legal one. BICMs can have long relationships with clients and their families and therefore witness circumstances and patterns of behaviour or situations which increase risk of harm, including from others in the wider community, both known and unknown. Participants discussed welfare issues associated with their clients, including being put at risk of financial mismanagement (particularly by family members and falling victim to scams). Vulnerability to substance misuse was discussed in relation to the right to make unwise decisions and of other professionals perceiving these as "lifestyle choices", and in relation to sexual behaviour where participants described clients who funded their drug habits through prostitution. Participants also highlighted that their clients' capacity to consent to sex was not considered and explained the difficulty they have with clients who are mistreated by unsuitable sexual partners, as intervening would deny them their autonomy.

Criminal behaviour also emerged as a theme, as clients were described as being manipulated by those involved in criminal activities such as drug dealing, theft and prostitution. Participants explained the challenges of having to explain to the police "why their clients behaved in a certain way and trying to explain the impacts of [...] the brain injury, so that they can see [that there's] [...] more to [...] what's gone on". This challenge was described as being due to the fact that "a lot of the impairments are invisible and therefore that person is judged in a way that certainly as case managers we don't want them to be judged". Living arrangements and homelessness were also mentioned, as well as participants explaining how they struggle with facilitating 
independence while their clients live in unsanitary conditions or lead sedentary lifestyles.

\begin{abstract}
"Client being used as an unpaid sex worker, extremely vulnerable in the community...drug using client who was sex working to fund her habit and other people's" (S32).

"A young male adult, was deemed to have capacity to live independently and manage a small budget. Client was particularly vulnerable and repeatedly lost/sold/gave away his possessions" (S60).
\end{abstract}

In relation to vulnerability, participants discussed the involvement of family members in the decision-making process. All participants felt the involvement of family members "very much depends on [...] the case manager's view of family" and "what matters to the client". Family involvement was seen by most to be "a careful balance [...] of family considerations and having to protect [...] the person with the brain injury from families often as well". All participants described this balance explaining that most family members are "incredible" as they "know everything about the client" and that they "see the patterns" and "they understand where the problems are". However, they also described how family members "sometimes can be quite destructive or can have their own agenda" where they did not have the client's best interests at heart.

Vulnerability was also linked to the inability of clients to access services, or only access to services unsuitable to their needs. This included the prison system, the NHS, housing associations, and social services. One participant described a client who "was supposed to go to prison" but they said that he should be in a rehabilitation unit, which he could not access due to finances. The NHS and social services deemed his criminal behaviour as "a lifestyle choice" and the housing association could not accommodate him because "he had too many needs". This resulted in the client being "stuck in a tent 
for 3 months". She explained how despite "ringing people every night" in an attempt to get someone to act, that this was met with the response "he has capacity".

Participants also argued that $A B I$ survivors were especially vulnerable because they "have no voice because of their [...] brain injury" and they felt it was part of their role to act as that voice for their clients.

"I had a client who [...] wanted to change the [...] care provider and $[. .$.$] the social worker was like fighting against him [...] he wasn't really being listened to$ at all [...] asked me to come in and [...] get his voice heard so we did that and the agency was changed then but [...] if he didn't have my help he could have just been left with an agency he wasn't happy with" (P12).

Finally, BICMs highlighted specific difficulties surrounding the "maturation process" of clients who had received their brain injury as a child and the challenge of achieving "a balance" between making "sure that clients are moving forwards [...] into adulthood" whilst dealing with family members who still viewed these individuals as children. The importance of facilitating positive risk and maintaining clients' right to make unwise decisions was emphasised. One participant exemplified how care is tailored to the individual as BICMs "have to make sure that we safeguard the client but maybe in a different way from how they have been when they were younger".

Theme 4: Implementation of the MCA and assessments: This final theme relates to the difficulties that participants raised about the use of the MCA, and the methods of assessment, with clients with $\mathrm{ABI}$. This was associated with sub-themes such as "unwise decisions" and discussions of the "constant [...] balancing act" between participants promoting their clients' autonomy and of their right to make unwise decisions, whilst protecting their welfare. Participants explained how promoting 
autonomy "empowers" clients and as "it's important that people have the feeling of being in control [as] [...] that's an essential part of any rehab". One participant stated that although difficult it is a crucial part of a BICM's job "to rehabilitate, not just not just protect and care". Multiple participants expressed the importance of taking "managed risks", as one participant stated that "risk aversion [...] just causes more problems" as it results in "conflict [...] lack of trust, [...] lack of [...] motivation and willingness [of clients] to work with the professionals".

Within the survey, $17 \%$ of participants compared working as BICMs before and after the MCA was implemented. One participant felt that "it's better than it was but it's not good enough" as "people who now are deemed to retain capacity or who may lack capacity but remain under review and then regain it would in the older days [...] be deemed to lack capacity" and that "more people are found to retain capacity now".

Whereas another described a client who she had worked with for 27 years who abused alcohol and whose rehabilitation "always broke down in the community" when "she goes in and out of rehab units or [...] hospitals". She said that despite this pattern of repeated unwise decisions "no one would pick her up" because the MCA rules that she has the right to make those unwise decisions. She explained that "the vulnerable clients are more vulnerable in my experience now than they were before [the MCA]" as this principle, as well as the principle that individuals must be assumed to have capacity until it is proven otherwise, meant that she could not get anyone to intervene in this case that "was getting higher risk by the minute".

As well as difficulties with the MCA, participants also referred to difficulties with the assessment process and structure; mainly that assessments too often take place oneto-one in office-based meetings in a "very time specific", "controlled" or "structured" 
environment and that this means that the effect on environment and distractors on the individual are not taken into account. The actual process of capacity assessments was also explored, largely focusing on who actually conducts them. Participants identified that clients are often "assessed through generic services [...] especially social services, who have absolutely zero understanding of brain injury and how people may present" and that "the things that [BICMs] [...] are pointing out are the things that they will miss or don't take into account'.

Participants also expressed concerns about how the MCA was applied to ABI. Here participants explained how capacity assessments are not tailored enough to $A B I$ as they do not account for the hidden disabilities that may influence them, particularly fluctuating capacity, executive dysfunction, and lack of insight. The general view was that although "there's a bit of a nod to brain injury" in the MCA itself, that "it's not really covered".

\footnotetext{
"Most of the brain injury barely comes into it in the in the code of practice it's all [...] dementia, people with learning disability, and the sorts of capacity issues that I deal with my clients so, 'does this person have capacity to be buying cocaine from the dealer that rings him?' 'Does this person have capacity to enter into a sexual relationship with a girl and does [...] he appreciate whether or not she's under 16? [...] there's nothing about any of that." (P6).
}

Within the survey, $92 \%$ of participants described the guidance within the MCA as unclear with the MCA failing to "give a definition really of what an 'unwise decision' is" and that the concept of unwise decisions is "hugely subjective". Furthermore, participants commented on how "if somebody lacks capacity, decisions have to be made in their best interests", yet "there is no definition in the actual guidance of what best interest actually is". Participants felt the guidance "should be much more refined and less open to interpretation", while many concluded that the problem lies in "the 
process surrounding" the principles as "there's no real enforcement of everybody doing it the same way".

Participants went on to provide suggestions for improvements to the MCA and capacity assessments for $A B I$ survivors, including the need for more specific guidance for $\mathrm{ABI}$ "particularly of looking at people who lack capacity and lack executive functioning". It was felt that the MCA "should specify that assessments of somebody with a brain injury are carried out by somebody that has some knowledge and experience [of ABI]" and that "there should be a need for people to look at the client over a longer period of time". It was also noted that "decisions should be made collectively" and that rules should be implemented to "make sure they've gathered evidence from other people". Participants stated that policy-makers should be "informed by practice", and how the sharing of information between assessors would aid their practice. One participant suggested that because "multiple agencies and [...] professionals all [work] [...] alongside each other but separately" that "some kind of centralisation of information of what assessments had taken place and [...] by which agencies and [...] documentation of these assessments" would benefit clients". She stated that the "recording [...] storing and sharing of information" might make assessments less subjective.

\section{Discussion}

This research aimed to explore the views of BICMs experiences of mental capacity, the MCA, and its relevant guidance, when applied to individuals with $A B I$ to 1) highlight potential conflicts or tensions that application of the MCA might pose and 2) identify approaches to mitigate the problems of the MCA and capacity assessments with individuals with $A B I$. The results suggest that $B I C M$ s had ongoing experience of clients 
with $A B I$ who have mental capacity issues, including multiple issues and fluctuating capacity. It further highlighted that participants working with clients with mental capacity issues often had disagreements with other services/professionals regarding the outcome of an MCA assessments and the application of the MCA guidance. Failing to take account of the nuances of $\mathrm{ABI}$ leads to clients becoming increasingly vulnerable within community settings. The findings identify the need for professional expertise and functional assessment as methods of mitigating the problems with the MCA and capacity assessments of those with $A B I$.

Participants consistently reported occasions where capacity assessment conducted by other professionals had led to assumptions of capacity in individuals with $A B I$ despite their opposing views. BICMs work long-term with clients and therefore have the opportunity to build therapeutic alliances and understanding of the clients and their families to support decision-making (Clark-Wilson and Holloway, 2015). Furthermore, supporting clients to make informed decisions is a key activity undertaken by BICMs (Clark-Wilson, 2006). This is in contrast to the working practice of other professionals who may be expected to do a mental capacity assessment where the time and resources are often unavailable to build up a complete picture of the person's functioning, build rapport with the client or include the involvement of trusted others involved in their care. This alongside a lack of expertise in $A B I$ often resulted in discrepancies between assessors who meet a client only very briefly and those that know the client best and over very lengthy time periods. The MCA code of practice encourages joint assessments with individuals that best know the client (George and Gilbert, 2018), however these results suggest this is not consistently practiced. 
This structure of assessment is particularly problematic when conducting capacity assessments with those with $\mathrm{ABI}$. The interview setting enables individuals with $\mathrm{ABI}$ to mask their disabilities, due to their intact intellect (Acquired Brain Injury and Mental Capacity Act Interest Group [ABIAMCAIG], 2014), intellectual awareness of their disability (Crosson et al., 1989), and intact language abilities (McCrea and Sharma, 2008), but also as their difficulties manifest outside of that structured environment (George and Gilbert, 2018). Decisions in reality are a complex and multi-faceted process and often require the integration and weighing up of multiple factors, which the MCA fails to take account of (Brown and Marchant, 2013). Within the assessment, it is the individuals stated intention in that moment that is assessed, rather than their actual functioning (ABIMCAIG, 2014; Dawson and McDonald, 2000). To the untrained eye, a client with intellectual awareness can present with a "cloak of competence" resulting in them appearing more capable during the assessment than they would be in a functional environment (Owen et al., 2018). This further demonstrates the issues with isolated assessments, and the need for the integration of information from those that know and understand the client out of this structured environment (Douglas and Bigby, 2018).

This problem with assessment is linked with a lack of knowledge and understanding of $\mathrm{ABI}$. One of the key issues highlighted by BICMs as a reason for this discrepancy is the assessors lack of knowledge regarding the impacts of $A B I$, particularly the hidden effects of executive dysfunction and insight. Langlois et al., (2006) commented that there is a tendency among professionals to overlook these invisible consequences of $\mathrm{ABI}$, thus overlooking the client's support needs. This lack of knowledge prevents assessors from seeing the nuances of brain injury and the limitations of the MCA for 
this population. This assumption of capacity and disregard for the hidden disabilities associated with $\mathrm{ABI}$ can leave clients in vulnerable positions without the appropriate safeguards in place (George and Gilbert, 2018).

The experiences given by BICMs often involved clients making repeated unwise decisions. Although the third principle of the MCA states that an individual should not be deemed to lack capacity based on unwise decision making ( $\mathrm{DoH}, 2005)$, it is often the very nature of unwise decisions (often repeatedly) that are a prominent concern for individuals with ABI (Lennard, 2016; Owen et al., 2017). The executive dysfunction and lack of insight following injury can impair an individual's ability to learn from previous experiences and mistakes, and to generalise this to guide future behaviour (Wood and Worthington, 2017). This can make the differentiation between unwise decisions made with and without capacity unclear (Hubbeling, 2014).

Participants in this study highlighted many examples of clients being left vulnerable as a result of assumptions of capacity. These examples reflect previous research that demonstrates an increased vulnerability and risk of homelessness (Hwang et al., 2008; Oddy et al., 2012; Topolovec-Vranic et al., 2012), incarceration (Mclsaac et al., 2016), financial mismanagement (Dreer et al., 2015), suicide (Fisher et al., 2016), abuse (Holloway and Lymbery, 2007; Mantell, 2010), self-neglect (Preston Shoot, 2018) and substance use (Weil et al., 2016) following ABI. A recent report by the All Party Parliamentary Group for ABI (APPG-ABI, 2018) highlighted some of these multiple risk factors, along with the need for ongoing community health and social care support following $\mathrm{ABI}$. 
Limitations: The participants in this study consisted of specialist BICMs across the UK. In order to provide a wider perspective of mental capacity following $A B I$ and to allow comparisons of experiences, the inclusion of other professional bodies may have provided a clearer picture of current practices and difficulties. Furthermore, the families of clients living with $\mathrm{ABI}$ may also have experiences regarding the MCA and assessment. Inclusion of this wider sample would have led to a more holistic understanding of the experiences of $\mathrm{ABI}$ and mental capacity.

Policy and Practice Implications: The study supports the findings from previous research recommending that health and social care professionals have more in-depth training regarding the invisible consequences of $\mathrm{ABI}$ and the effect this has on decision making (ABIMCAIG, 2014; Flynn 2016; Norman, 2016). The principles of the MCA are focused on ensuring that decisions about care are aligned closely with the wishes of clients, and the importance of personalised care where it is assumed that service users are best placed to understand their individual needs (Dickinson and Glasbery, 2010). The difficulties associated with executive dysfunction and lack of insight mean that this perspective is sometimes unrealistic, and at points, a dangerous approach to apply in some cases of individuals with ABI (Preston-Shoot, 2018; Holloway and Fyson, 2016). Further training is required to support professionals in their understanding of these factors when assessing capacity.

Where possible, assessments should not be conducted in isolation, rather assessors should either know the client, or take the time to know the client and their circumstances (Douglas and Bigby, 2018). Information from trusted others, for example family members and professionals, that know the client well should be incorporated into assessments, with professionals ensuring they do not take 
information from office-based interviews at face value. It is important for professionals to possess knowledge of the client's pre-injury history and post-history functioning through collaboration with professionals and family members (Flynn, 2016; Norman, 2016).

Finally, changes within the MCA guidance and its application should be considered to take into account the complex needs and hidden effects of $A B I$ to help safeguard individuals affected by $A B I$. It is important for professionals to move away from performing office-based assessments of capacity, based upon verbal output alone, and instead consider routinely using more functional assessments of capacity that are more likely to detect the invisible disabilities associated with $\mathrm{ABI}$. Resources to support decision-making should either be made more explicit or be adapted for use with $A B I$. Changes need to be considered to the way in which "unwise decisions" are classified within mental capacity assessments. The current MCA guidance is unclear with regard to the principles of unwise decisions in terms of how to incorporate treating capacity as decision-specific alongside the consideration of repeated unwise decisions associated with poor executive impairment (Mantell, 2010).

Since this research was conducted, the National Institute for Clinical Excellence (NICE) has updated the guidelines for the MCA (NICE, 2018). This new guidance recommends the need for training amongst professionals, assessors and advocates in supporting people who have communication difficulties and specifically refers to the need for training in understanding condition-specific deficits, such as those associated with brain injury. Furthermore, the guidance concluded that with consent, professionals should seek to involve relevant others in the assessment process to 
create a "complete picture of the person's capacity". Specific reference is also made to the need to be aware of the difficulties associated with executive dysfunction. It is hoped that these guidelines will go some way to improving future practice, yet further consultation into updating the code of practice has been noted as important for ensuring those with $A B I$ are appropriately supported by the legislation (UK Acquired Brain Injury Forum, UKABIF, 2019)

Furthermore, a recent priority setting partnership conducted in association with the James Lind Alliance identified 10 priorities for future research in the area of adult social work (Department of Health \& Social Care [DoHSC, 2018). Top ten priorities included research into; the ways in which adult social care professionals interact with those with communication difficulties, how the MCA is embedded into practice, and the need to explore partnership working with other health and social care practitioners. All these priorities fit with the findings of this research - the need for a better understanding of the deficits associated with $\mathrm{ABI}$, an improved understanding of the MCA and how it relates to those with $\mathrm{ABI}$, and a need for collaboration in mental capacity assessments with other professionals. Although it did not make it into the top ten, the need for research into more effective ways of working with people with $A B I$ was ranked $11^{\text {th }}$ (DoHSC, 2018).

In conclusion, this study has highlighted the experiences and issues BICMs face regarding the capacity of their clients and the application of the MCA. The MCA is currently not appropriately applied to support safeguarding these individuals, resulting in them making repeated unrealistic and unwise decisions that can sometimes be unintentionally self-harming/self-sabotaging. Training should be offered to non- 
specialist assessors working with clients to highlight the hidden effects of $A B I$. Changes need to be made to the assessment processes undertaken under the MCA to take into account the complicated and diverse effects of brain injury, particularly executive dysfunction and insight, in order that assessments are informed by more than verbal output alone.

\section{Acknowledgements:}

Special thanks to the British Association of Brain Injury Case Managers (BABICM) for supporting this research study and enabling recruitment through their membership. 


\section{References}

Acquired Brain Injury and Mental Capacity Act Interest Group. (2014) Making the Abstract Real: Recommendations for action following the House of Lords Select Committee Post-Legislative Scrutiny Report into the Mental Capacity Act. Available at: http://www.biswg.co.uk/blog/acquired-brain-injury-andmental-capacity-making-abstract-re/ (Accessed 20 August 2018).

Austin, Z. and Sutton, J. (2014), Qualitative research: getting started. The Canadian Journal of Hospital Pharmacy, 67, 436-440.

Beadle-Brown, J. (2015), Supported decision-making in the United Kingdom: Lessons for future success. Research and Practice in Intellectual and Developmental Disabilities, 2, 17-28.

Bombardier, C. H. Temkin, N. R. Machamer, J. et al. (2003), The Natural History of Drinking and Alcohol-Related Problems After Traumatic Brain Injury. Archives of Physical Medicine and Rehabilitation, 84, 185-191.

Braun, V. and Clarke, V. (2006), Using thematic analysis in psychology. Qualitative Research in Psychology, 3, 77-101

Brown, H. and Marchant, L. (2013), Using the Mental Capacity Act in complex cases. Tizard Learning Disability Review, 18, 60-69.

Case, P. (2016). Dangerous liaisons? Psychiatry and law in the Court of ProtectionExpert discourses of 'insight'(and 'compliance'). Medical law review, 24, 360378.

Chan, R. C. K. Shum, D. Toulopoulou, T. et al., (2008), Assessment of executive functions: Review of instruments and identification of critical issues. Archives of Clinical Neuropsychology, 23, 201-216. 
Clark-Wilson, J. (2006), "What is brain injury case management?" in Parker, J (Ed). Good Practice in Brain Injury Case Management. Jessica Kinsley Publishers: London:

Clark-Wilson, J. and Holloway, M. (2015), Life care planning and long-term care for individuals with brain injury in the UK. Neurorehabilitation, 36, 289-300.

Creswell, J.W. Plano, C.V.L. Gutmann, M.L et al., (2003), "Advanced mixed methods research designs". In Tashakkori, A, \& Teddlie, C (Eds.), Handbook of Mixed Methods in Social and Behavioural Research. Sage: Thousand Oaks, CA

Crosson, B. Barco, P.P. Velozo, C.A. et al. (1989), Awareness and compensation in post-acute head injury rehabilitation. Journal of Head Trauma Rehabilitation, $4,46-54$.

Dawson, C and McDonald, A. (2000), Assessing mental capacity: a checklist for Social workers. Practice, 12, 5-20.

Department of Health. (2005), Mental Capacity Act. London: HMSO. Available at: http://www.legislation.gov.uk/ukpga/2005/9/contents. (Accessed: 25 April 2018).

Department of Health and Social Care (2018). Priorities for adult social work research. Results from the James Lind Alliance Priority setting partnership for adult social care. Available at: http://www.jla.nihr.ac.uk/priority-setting-partnerships/adultsocial-work/downloads/Adult-Social-Work-PSP-final-report.pdf (Accessed 22 December 2018).

Dickinson, H. and Glasbery, J. (2010), The Personalisation Agenda: Implications for the Third Sector. Third Sector Research Centre: Birmingham, UK. 
Dreer, L.E. DeVivo, M.J. Novack, T.A. et al. (2012), Financial Capacity Following Traumatic Brain Injury: A Six-Month Longitudinal Study. Rehabilitation Psychology, 57(1), 5-12.

Douglas, J.M. and Bigby, C. (2018), Development of an evidence-based practice framework to guide decision making support for people with cognitive impairment due to acquired brain injury or intellectual disability. Disability and Rehabilitation, DOI: 10.1080/09638288.2018.1498546

Felmingham, K.L, Baguley, I.J, and Green, A.M. (2004), Effects of diffuse axonal injury on speed of information processing following severe traumatic brain injury. Neuropsychology, 18, 564-571.

Fisher, L.B. Pedrelli, P. Iverson, G.L. et al. (2016), Behaviour following traumatic brain injury: Longitudinal follow-up data from the NIDRR Traumatic Brain Injury Model Systems. Brain Injury, 30, 1311-1218.

Fleminger, S. and Ponsford, J. (2005), Long term outcome after traumatic brain injury. British Medical Journal, 331, 1419-1420.

Flynn, M. (2016) The death of 'Tom': A Serious Case Review. Somerset Safeguarding Adults Board. Available at: https://www.headway.org.uk/media/4752/tom-sar-final-june-2016.pdf. (Accessed 10 January 2018).

George, M. and Gilbert, S. (2018), Mental Capacity Act (2005) Assessments: Why everyone needs to know about the frontal lobe paradox. The Neuropsychologist, 5, 59-66.

Gioia, G. Isquith, P. and Kenealy, L. (2008), Assessment of Behavioral Aspects of Executive Function. In: Anderson, V. Jacobs, R. and Anderson, P. (eds.) 
Executive functions and the frontal lobes: a lifespan perspective. Psychology:

Hove.

Hanson, W.E. Creswell, J.W. Clark, V.L. et al. (2005). Mixed methods research designs in counselling psychology. Journal of Counselling Psychology, 52, 224-235.

Hardie, E. and Brooks, L. (2009), Brief guide to the Mental Capacity Act 2005: Implications for people with Learning Disabilities. British Institute of Learning Disabilities: Worcestershire, UK.

Headway. (2018). Statistics. Headway: the brain injury association. Available at: https://www.headway.org.uk/about-brain-injury/further-information/statistics/ (Accessed 25 April 2018).

Higham, P. and Phelps, K. (1998), Careers of Care: Survivors of Traumatic Brain Injury and the Response of Health and Social Care. Ashgate Publishing Ltd: Farnham, UK

Holloway, M. (2014), How is $A B I$ assessed and responded to in non-specialist settings? Is specialist education required for all social care professionals? Social Care and Neurodisability, 5, 201-213.

Holloway, M and Fyson, R (2016), Acquired Brain Injury, Social Work and the Challenges of Personalisation. British Journal of Social Work, 46(5),1301-1317. Holloway, M. and Lymbery, M. (2007). Caring for people: social work with adults in the next decade and beyond. The British Journal of Social Work, 37, 375-386. Homaifar, B.Y, Brenner L, Forster, J.E. et al. (2012), Traumatic Brain Injury, Executive Functioning, and Suicidal Behaviour: A Brief Report. Rehabilitation Psychology, 57(4), 337-341 
House of Lords Select Committee on the Mental Capacity Act 2005. (2014), Mental Capacity Act 2005: post-legislative scrutiny. House of Lords: London, UK.

Hsieh, H.F. and Shannon, S.E. (2005), Three approaches to qualitative content analysis. Qualitative Health Research, 15(9), 1277-1288.

Hubbeling, D. (2014), Decision-making capacity should not be decisive in emergencies. Medicine, Health Care and Philosophy, 17, 229-238.

Hwang, S.W. Colantonio, A, Chiu, S. et al. (2008), The effect of traumatic brain injury on the health of homeless people. Canadian Medical Association Journal, 179, 779-784.

Khan, F. Baguley, I.J. and Cameron, D. (2003), Rehabilitation after traumatic brain injury. MJA Practice Essentials, 178, 290-295.

Lennard, C. (2016), Fluctuating capacity and impulsiveness in acquired brain injury: the dilemma of unwise decisions under the Mental Capacity Act. Journal of Adult Protection, 18, 229-239.

Manchester, D. Priestley, N. and Jackson, H. (2004), The assessment of executive functions: coming out of the office. Brain Injury, 18, 1067-1081.

Mantell, A. (2010). Traumatic brain injury and potential safeguarding concerns. Journal of Adult Protection, 12, 31-42.

Marshall, H. and Sprung, S. (2017), The Mental Capacity Act: 'Best interests' - a review of the literature. British Journal of Community Nursing, 22(8), 384-390.

Mathias, J. L. and Mansfield, K. M. (2005). Prospective and declarative memory problems following moderate and severe traumatic brain injury. Brain Injury, 19, 271-282. 
McCrea, J. and Sharma, R. (2008), "Training staff to work with clients with executive disorder". In Oddy, M. and Worthington, A. (Eds.), The Rehabilitation of Executive Disorders: A Guide to Theory and Practice. Oxford University Press: Oxford.

Mclsaac, K.E. Moser, A. Moineddin, R. et al. (2016), Association between traumatic brain injury and incarceration: A population-based cohort study. CMAJ Open, 4, 746-753.

Miles, M. B. and Huberman, A. M. (1994), Qualitative Data Analysis: An Expanded Sourcebook. Sage: Thousand Oaks, CA.

National Institute for Clinical Excellence (NICE). (2018). Decision-making and mental capacity. NICE guideline [NG108]. Available at:

https://www.nice.org.uk/guidance/ng108/chapter/Recommendations-forresearch\#1-training-and-support-for-practitioners. (Accessed 22 December 2018).

Norman A. (2016), A preventable death? A family's perspective on an adult safeguarding review regarding an adult with traumatic brain injury. Journal of Adult Protection, 18(6), 341-352

Oddy, M. Moir, J. Fortescue, D. et al. (2012), The prevalence of traumatic brain injury in the homeless community in a UK city. Brain Injury, 26, 1058-1064.

Owen, G. ., Freyenhagen, F., \& Martin, W. (2018) Assessing Decision-Making Capacity After Brain Injury: A Phenomenological Approach. Philosophy, Psychiatry, \& Psychology, 25(1), 1-19.

Owen, G.S. Freyenhagen, F. Martin, W. et al. (2017), Clinical assessment of decision-making capacity in acquired brain injury with personality disorder. Neuropsychological Rehabilitation, 27(1), 133-48. 
Ownsworth, T. Clare, L. and Morris, R. (2006), An integrated biopsychosocial approach to understanding awareness deficits in Alzheimer's disease and brain injury. Neuropsychological Rehabilitation, 16, 415-438.

Parry-Jones, B.L. Vaughan, F.L. and Cox, W.M. (2004), Traumatic brain injury and substance misuse: A systematic review of prevalence and outcomes research (1994-2004). Neuropsychological Rehabilitation, 16(5), 537-560.

Parsons, T.D. Carlew, A.R. Magtoto, J. et al. (2017), The potential of function-led virtual environments for ecologically valid measures of executive function in experimental and clinical neuropsychology. Neuropsychological Rehabilitation, 27, 777-807.

Patton, M.Q. (2002), Qualitative Research and Evaluation Methods. Sage: Thousand Oaks, CA.

Preston-Shoot, M. (2018), Learning from safeguarding adult reviews on self-neglect: addressing the challenge of change. Journal of Adult Protection, 20, 78-92.

Prigitano, G.P. (2005), Disturbances of Self-awareness and Rehabilitation of Patients with Traumatic Brain Injury: A 20-Year Perspective. Journal of Head Trauma Rehabilitation, 20, 19-29.

Rabinowitz, A.R. and Levin, H.S. (2014), Cognitive sequelae of traumatic brain injury. Psychiatric Clinics of North America, 37, 1-11.

Ravalier, J. M. (2018), Psycho-social working conditions and stress in UK social workers. British Journal of Social Work, bcy023, https//doi.org/10.1093/bjsw/bcy023. 
Rohling, M. L., Faust, M. E., Beverly, B., \& Demakis, G. (2009). Effectiveness of cognitive rehabilitation following acquired brain injury: A meta-analytic reNeuropsychology, 23, 20-39.

Ruck Keene, A., Kane, N. B., Kim, S. Y. \& Owen, G. S. (2019). Taking capacity seriously? Ten years of mental capacity disputes before England's Court of Protection. International journal of law and psychiatry, 62, 56-76.

Rutland-Brown, W. Langlois, J.A. Thomas, K.E. et al. (2006), Incidence of traumatic brain injury in the United States, 2003. Journal of Head Trauma Rehabilitation, 21, 544-548.

Simpson, G. and Tate, R. (2002), Suicidality after traumatic brain injury: demographic, injury and clinical correlates. Psychological Medicine, 32, 687697.

Tesch, R. (1990), Qualitative Research: Analysis Types and Software Tools. Falmer: Bristol, UK.

Thornton, T. (2011), Capacity, Mental Mechanisms, and Unwise Decisions. Philosophy, Psychiatry, \& Psychology, 18(2), 127-132

Topolovec-Vradnic, J. Ennis, N. Colantonio, A. et al. (2012), Traumatic brain injury among people who are homeless: a systematic review. BMC Public Health, 12, 1059.

UKABIF (2019). Letter: Mental Capacity Act Code of Practice: Call for evidence.

Retrieved 08/05/19: https://www.ukabif.org.uk/wp-

content/uploads/2019/03/Acquired-Brain-Injury-Collaboration-MCA-CoP-

Submission-6-March-2019.pdf 
Weil, Z.M. Corrigan, J.D, and Karelina, K. (2016), Alcohol abuse after traumatic brain injury: Experimental and clinical evidence. Neuroscience and Behavioural Reviews, 62, 89-99

Williams, V. Boyle, G. Jepson, M. et al. (2012), Making Best Interest Decisions:

People and Processes Policy Research Programme. Department of Health: London, UK.

Wood, R.L. and Worthington, A. (2017). Neurobehavioral abnormalities associated with executive dysfunction after traumatic brain injury. Frontiers in Behavioural Neuroscience, 11, 195.

Yates, P.J. Williams, W.H. Harris, A. et al. (2006), An epidemiological study of head injuries in a UK population attending an emergency department. Journal of Neurology, Neurosurgery \& Psychiatry, 77, 699-701. 


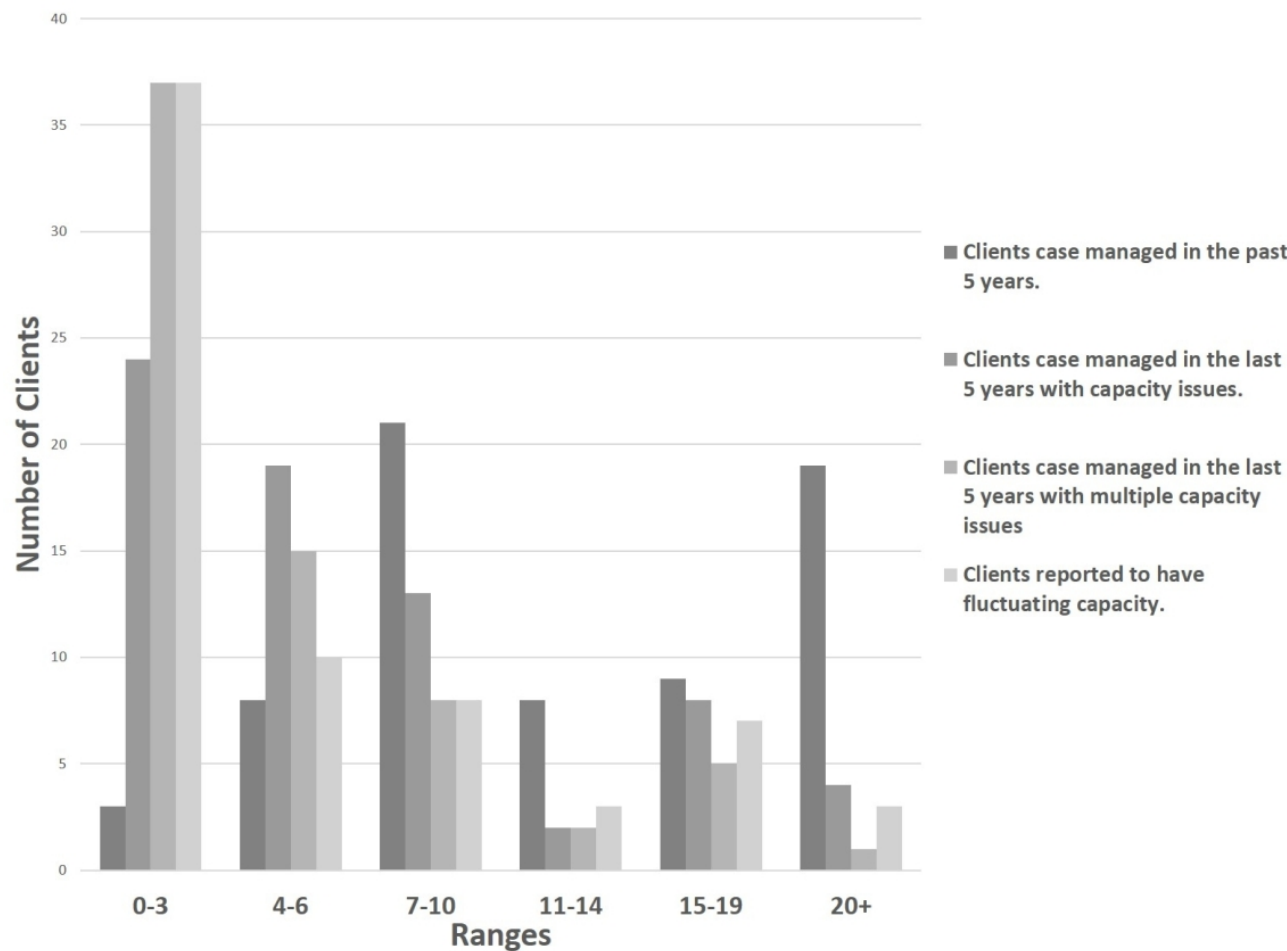

Number of clients managed in the last five years

$268 \times 197 m m(150 \times 150$ DPI $)$ 


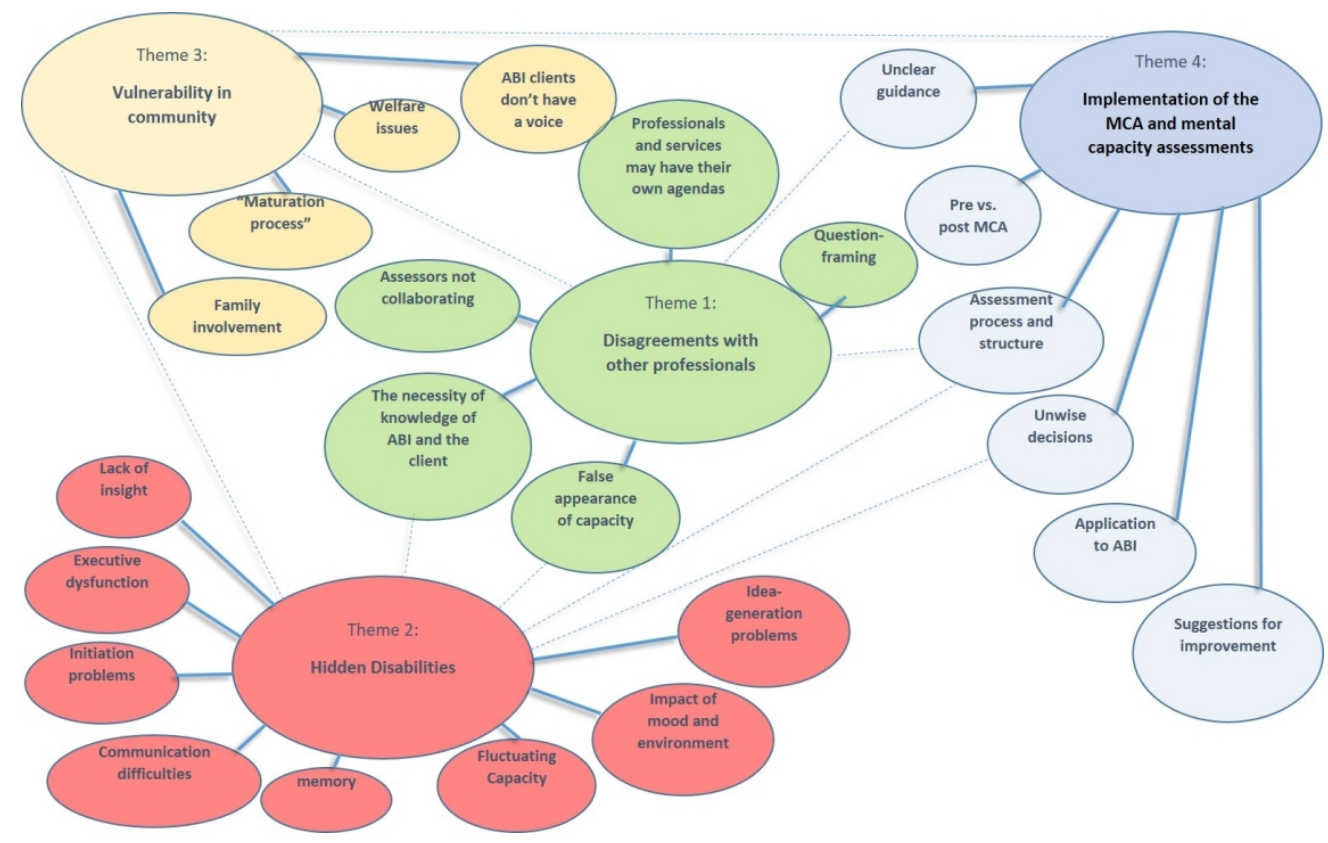

Thematic Map

$270 \times 170 \mathrm{~mm}(150 \times 150 \mathrm{DPI})$ 